\title{
Rethinking our Practice and Choosing a Topic for TESOL International Association 2014 and MIDTESOL 2013
}

Marcellino Berardo

\section{Introduction to the Supplement}

A key reason for launching ILI at AEC is to help us rethink our practice and improve professionally through the exchange of ideas, techniques, materials, assessments, reflections, and so on. This supplement offers ways to think about practicing and interpreting TESL within the framework of TESOL International Association ${ }^{1}$ and MIDTESOL. TESOL's framework consists of three parts: (a) Interest Sections, (b) Content Areas, and (c) types of sessions. TESOL also has conference themes that we can use to help us reimagine our practice. Similarly, MIDTESOL has conference themes and session types but unlike the international organization, MIDTESOL does not require interest section affiliation and does not categorize presentations according to content area.

Viewing our work and career from the organizational perspective of TESOL and MIDTESOL can lead to a reconceptualization of our instruction, service, professional growth, administrative activities, and research and development. This organizational perspective on our work can also help us organize thoughts for writing a proposal for TESOL 2014 or for MIDTESOL 2013. To facilitate a "rethink" of our practice and to stimulate ideas for proposals, we offer this Supplement to ILI at AEC Volume 2.

\section{Interest Sections, Content Areas and Types of Sessions ${ }^{2}$}

\section{Interest Sections}

One way to rethink our practice is to reconsider which TESOL communities or Interest Sections we currently belong to or would like to belong to. Some Interest Sections that are relevant to AEC faculty include: (a) Intensive English Programs, (b) Higher Education, (c) Program Administration, (d) Computer-Assisted Language Learning, (e) Intercultural Communication, (f) Materials Writers, (g) Second Language Writing, (h) Speech, Pronunciation, and Listening, (i) Applied Linguistics, and (j) Nonnative English Speakers in TESOL.

\section{Content Areas}

We can also reconsider our work by classifying it according to TESOL's categories for content areas. ${ }^{3}$ Some important content areas relevant to the AEC are: (a) Accreditation , (b) Assessment and Testing, (c) Classroom Management , (d) Content-based Language Instruction, (e) Grammar, (f) Second Language Acquisition, (g) Social Responsibility,

Tips for Writing Proposals for TESOL Mark Algren

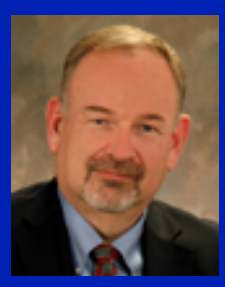

I co-presented (along with other former TESOL Convention Chairs) an annual session entitled Tips for Writing TESOL International Convention Proposals. In the past two years, TESOL has strengthened the rubric for assessing proposals, and now focuses even more strongly on evaluating content. The acceptance rate for TESOL conferences runs around $23-25 \%$, so acceptance is an honor. If you have never made a presentation at a TESOL convention, or if you have written a proposal and it has not been accepted, you should review this session PowerPoint to learn what makes a proposal acceptable and to get help framing your professional interest and expertise into a proposal. I am happy to send you a pdf of the PowerPoint or you can access the

presentation at

http://www.ericsdwyer.info/tesol2014prez.p pt.

(h) Teacher Education, (i) Curriculum, Materials Development, and (j) Vocabulary, Lexicon.

\footnotetext{
${ }^{1}$ TESOL's official name is TESOL International Association. Rather than using the full name, I refer to the organization as TESOL.

${ }^{2}$ See Appendix for a complete list of interest sections, content areas, and types of sessions.

${ }^{3}$ Some names for content areas overlap with names for Interest Sections. Overlapping names are not included in this brief list.
} 
Types of Sessions

When preparing a proposal for TESOL or MIDTESOL, it is important to think about the best way to present it. TESOL has fourteen different types of sessions that allow for a variety of ways to present topics. Some session types are researchoriented and practice-oriented. Other types of sessions are discussion groups, colloquia, and academic sessions. Teacher tips and poster sessions are other ways to communicate ideas at TESOL. ${ }^{4}$ MIDTESOL has four "styles of presentation" (1) new research, (2) demonstration, (3) discussion, and (4) other.

Categories in Table 1 show the interest sections, content areas, and session types that are relevant to our colleagues who presented at this year's TESOL's conference.

Table 1

Interest Sections, Content Areas and Presentation Types Chosen by AEC Faculty for TESOL 2013

\begin{tabular}{llll}
\hline Presentation & Interest Section & Content Area & Type of Session \\
\hline 1 & Intensive English Program & Program Administration & Research-oriented \\
2 & Intensive English Program & Intensive English Program & Discussion Group \\
3 & Program Administration & Intensive English Program & Practice-Oriented \\
4 & Intensive English Program & Computer-Assisted Language Learning & Practice-Oriented \\
5 & Higher Education & Social Responsibility & Research-oriented \\
6 & Program Administration & Higher Education & Colloquium \\
7 & Higher Education & Speech, Pronunciation, and Listening & Academic Session \\
\hline
\end{tabular}

Tables 2 and 3 offer a closer look at selected content areas within TESOL by listing titles of presentations that were classified according to content areas. The content areas come from Table 1 to ensure relevance to AEC faculty and administrators.

Table 2

Selected Titles of Presentations by Content Areas: Computer-Assisted Language Learning (CALL), Higher Education (HE), and Intensive English Programs (IEP).

\begin{tabular}{lll}
\hline CALL & HE & IEP \\
\hline Maximizing Blackboard & Harmonious Transitions for & 'Talk to Me’: An Authentic \\
Use: From Research to & University Success & Oral Skills Assessment for \\
Practice & & ELL’s
\end{tabular}

It's Alive! Blending

Technology with Academic

Materials for Engaged

Out and About: Fostering

Communication With Task-

Based Speaking Activities

Learning (Marvin-Peixoto

\&McClintic)

In Perfect Harmony: Mobile

Devices and Language

Learning
Action Research: A

Performance-Based Project to

Promote Active Learning
Benefits of a Content Lecture

Course in an IEP Curriculum
A Professional Reading Group

for EAP Instructors

\footnotetext{
${ }^{4}$ Poster sessions are not included in the official TESOL category of Session Types. I include poster sessions because they are a part of TESOL and they are another way to think about how to communicate an innovation or insight.
} 
Self-editing Software for Students

Smart Use of Smart Phones

Obstacles to Opportunities: Integrating iPads into an IEP Curriculum

Let Your Traditional Classroom Prepare Your Students for Online Classes

Making It Meaningful: Writing Feedback With Videos and Hyperlinks
Reading for Research: An Academic Portfolio Project

Flipped Classroom: Applying Academic Strategies in Textbooks to Authentic Materials

Initiatives to Promote Student Success at University-Based IEP's (Issa, Tilson, et al.)

How Teachers, Administrators, and Institutions Can Facilitate Teacher Collaboration

Exploring the International Undergraduate Experience: Harmonizing Voices, Honoring Differences
Factors Influencing Chinese ESL Students' Social, Cultural, and Academic Transitions

Using Sustained Content for Writing Classes

Saudi Women as ESL Students: Expectations, Challenges, and Solutions

Addressing the Needs of ZeroLevel Learners in an IEP (Gould \& Taveggia)

Retaining Middle Eastern Students through Cultural Harmonizing (Algren \& Kanaan)

Table 3

Selected Titles of Presentations by Content Areas: Program Administration (PA), Social Responsibility (SR), Speech, Pronunciation, Phonology, and Listening (SPL).

\begin{tabular}{lll}
\hline PA & SR & SPPL \\
\hline $\begin{array}{l}\text { Developing Strategic } \\
\text { Planning Skills for Language }\end{array}$ & $\begin{array}{l}\text { TESL/TEFL and } \\
\text { Supporting Linguistic } \\
\text { Diversity in Higher } \\
\text { Education (Berardo \& } \\
\text { Hirata-Edds) }\end{array}$ & $\begin{array}{l}\text { Teaching Basic English Intonation by Non- } \\
\text { native English Speaking Teachers }\end{array}$ \\
$\begin{array}{ll}\text { ESL Program Design: The } \\
\text { Un-Classroom }\end{array}$ & $\begin{array}{l}\text { Broadcasts and Podcasts } \\
\text { Deliver Oral Skills and } \\
\text { Multicultural } \\
\text { Understanding }\end{array}$ & $\begin{array}{l}\text { Issues, Principles and Practice in the } \\
\text { Improvement of Productive Skills (Forth et al.) }\end{array}$ \\
&
\end{tabular}

Binational Collaboration

Broadens Professional

Horizons for Mexican

Teachers of English

Discerning Teacher Supervision and Evaluation to Promote Teacher Growth

Student Complaints About Faculty: Where to Start, Where to Go (Issa \& McGuinness)
Service Learning and Teaching ESL: A Harmony of Ideals

Creating Global Citizens: Socially Responsible Educators in ESL Classrooms

Our Nondiverse Teaching Force: Origins, Implications, and Remedies
Teaching Listening: From Perception to

Comprehension

Anchoring Academic Word List Vocabulary: One Touch at a Time

Using Authentic Online Lectures to Promote Presentation and Speaking Skills 
An Online Community for Harmonizing Faculty and Staff Professional

Development

The Harmony of Change: Accreditation to Innovation
Occupy the Classroom: Getting the Students Involved

Content Integration Strategies to Reach Ethnic Tolerance
Customizing Rubrics: Making Speaking

Assessment More Reliable and Less Painful
Recording Student Speaking:

Suggestions for Every Teacher's Toolkit

\section{Considering the Conference Theme}

Another way to view our practice through TESOL is to consider the themes of the conferences. The conference theme or variations of the theme appear in many of the presentation titles. This year's theme was "Harmonizing Language, Heritage, \& Culture.” Here are 10 examples of presentation titles with a version of the theme in the title. The first example is the plenary from the current President of TESOL. The rest are from the first day of the conference. Following the titles, in parentheses, are the Interest Section, Content Area, and Type of Session.

- $\quad$ Our Heritage: The TESOL Journey in Developing Great Teachers, by Suzanne Panferov, President of TESOL International Association.

- Harmonizing Principles, Practices, Standards, and Outcomes through Proven Program Design (Program Administration; Intensive English Programs; Discussion Group).

- Harmonizing Student-Led Discussion Outcomes with University Level Expectations (Higher Education; Contentbased Language Instruction; Practice-Oriented).

- Harmonizing Nontraditional Assessments with a Traditional Culture (EFL; Assessment and Testing; ResearchOriented).

- Mobile English: Harmonizing Traditional Language Practice and New Technology Devices (EFL; Technology in Education; Practice-Oriented).

- Phonology in L2 Reading: Harmonizing "Expert” Voices in Classroom Research (Higher Education; ReadingLiteracy; Research-Oriented).

- Harmonizing EFL Practices: Neuroscientific Research (EFL; Other; Academic Session).

- Harmonious Transitions for University Success (Higher Education; Higher Education; Practice-Oriented).

- Considering Language, Heritage, and Culture in Assessment (EFL; Assessing and Testing; Practice-Oriented).

- Creating a Harmonious and Dynamic Listening and Speaking Tutor Program (Higher Education; Intensive English Programs; Practice-Oriented).

Whether we are rethinking our practice or submitting a proposal to TESOL, it can be productive to consider interest sections, content areas, and conference themes. If preparing a proposal, it is important to consider session types and styles of presentation.

Information about TESOL 2014: 48th Annual TESOL Convention and Exhibit

Place: $\quad$ Portland, Oregon

Date: $\quad$ March 26-29, 2014

Submit Proposals: $\quad \underline{\text { http://www.tesol.org/convention2013/2014-convention-proposals }}$

Deadline: $\quad$ June 3, 2013

More Information: http://www.tesol.org

Program Book for 2013:

http://www.tesol.org/docs/tesol-convention/tesol-2013-final-program_final_low.pdf?sfvrsn=2 